Article

\title{
Decreasing the Impact of Anxiety on Cancer Prevention through Online Intervention
}

\author{
Maksymilian Gajda *(D) and Małgorzata Kowalska $(\mathbb{D}$ \\ Department of Epidemiology, School of Medicine in Katowice, Medical University of Silesia, \\ 40-055 Katowice, Poland; mkowalska@sum.edu.pl \\ * Correspondence: mgajda@sum.edu.pl; Tel.: +48-32-25-23-734
}

Received: 23 December 2019; Accepted: 3 February 2020; Published: 5 February 2020

check for updates

\begin{abstract}
Background: Low levels of public knowledge, incorrect beliefs, and anxiety are the most often mentioned factors that may negatively affect the implementation of preventive campaigns and timely diagnosis of cancer. Cancer is a major unresolved problem for global public health. As a result, many effective preventive measures need to be found and implemented. Methods: For a duration of 18 months, readers of the Polish scientific Internet portal were invited to participate in the Polish On-line Randomized Intervention aimed at Neoplasm Avoidance (PORINA) study. Level of cancer-related anxiety was our main measure (self-declared on a simple five-point Likert scale) in this analysis. Results: A total of 463 participants were qualified for the final analysis. Respondents with a positive family history of cancer $(p<0.001)$ declared the highest level of cancer-related anxiety, whereas lower levels were declared by those previously treated for cancer $(p=0.006)$. The conducted educational intervention reduced the declared level of cancer-related anxiety. Conclusions: The results of this study provide evidence that the use of web-based interventions aimed at increasing awareness could reduce cancer-related anxiety and may lead to more frequent consent to undergo some of the medical procedures used to diagnose or treat cancer.
\end{abstract}

Keywords: anxiety; cancer; prevention; online; intervention

\section{Introduction}

Many factors negatively impact the implementation of preventive health campaigns. These factors also contribute to a delay in the scheduling of patient visits to the doctor. Late diagnosis and subsequently delayed treatment often lead to worse prognoses. The insufficient level of society's knowledge, current beliefs, anxiety, embarrassment, and cultural factors may contribute to this situation [1-13]. So far, many actions have been taken to reduce the widespread misconceptions about cancer and associated stigmatization. Such activities have been added, among others, to the World Cancer Declaration of 2013 (Union for International Cancer Control) and the World Cancer Declaration of 2011 (goal no. 5) [14]. Unfortunately, cancer is still a significant and unresolved global public health problem, and more effective preventive procedures need to be found. At the same time, Internet resources are becoming one of the primary sources of knowledge about cancer [15-18]. Web-based features are increasingly being used by public health researchers [19-21]. In 2003, a social support program conducted via the Internet effectively reduced the level of depression, stress, and anxiety associated with cancer treatment [22]. Embarrassment and fear are included among the factors that negatively affect the tendency of men to search for medical information [23,24]. Many studies conducted so far involving both patients diagnosed with cancer and cancer survivors investigated the effectiveness of interventions in reducing the level of disease-related anxiety [25-28]. To the best of our knowledge, whether this type of activity is also possible in the non-patient population of Central Europe has not yet been established. 


\section{Materials and Methods}

Here, we present the most important information necessary for assessing the relationship between the level of knowledge and anxiety associated with cancer. A more comprehensive description of the protocol of the Polish On-line Randomized Intervention aimed at Neoplasm Avoidance (PORINA) study was included in our previous papers on the PORINA study $[29,30]$ as well as in a doctoral thesis (available upon request).

\subsection{General Description of the Study}

From 14 May 2015 to 13 November 2016, all readers of the publicly available Polish scientific Internet portal were invited to participate in the Polish On-line Randomized Intervention aimed at Neoplasm Avoidance (PORINA) study. A dedicated internet platform was created to allow the study to be conducted, including obtaining electronic informed consent. Before granting voluntary consent, visitors were provided all information about the study including its anonymity, aims, and stages. Participants were randomly assigned (1:1) to two groups: control or interventional. All subjects were asked to complete our questionnaire two times (baseline and final assessment). Through the evaluation of questionnaires obtained from participants in the control group, we were able to successfully validate the tool [29]. Subjects assigned to the intervention group were provided access to educational material and were required to participate in a simple quiz. This process allowed us to verify whether they were acquainted with the educational content. Failure to complete the quiz held participants back from the next phase of the study. In this case, the subjects were asked to re-enter the educational module [29,30].

\subsection{Data Assessment and Main Measures}

Our questionnaire contained only closed-ended questions written in Polish. This allowed us to assess demographic data, subjects' general knowledge on cancer, and their attitude toward undergoing selected medical procedures applicable to the diagnosis and treatment of cancer, and evaluate the source of information on cancer. Participants were also asked to self-declare their anxiety associated with selected disease entities (including cancer). For this purpose, a simple 5-point Likert scale was used where the value 1 indicated the lowest level of anxiety and 5 indicated the highest level. The level of anxiety was our main measure in the current analysis. As described in our previous publications, the original Cancer Knowledge Index (CKI) was used to evaluate participants' cancer-related knowledge. It was calculated based on the answers to a set of 20 questions (value range from 0 to 20). Three levels of CKI were distinguished based on tertile distribution $[29,30]$.

\subsection{Statistical Analysis and Ethical Approval}

All statistical analyses were conducted with R software [31] and $p$-values less than 0.05 were considered statistically significant. We analyzed simple descriptive statistics, difference tests, and logistic regression models in which the level of anxiety was a dependent value and independent values included the participants' age, sex, place of residence, occupation, level of education, family history of cancer, personal history of cancer, being treated for cancer, self-assessment of cancer-related level of knowledge, and self-declaration of willingness to improve the level of cancer-related knowledge. Given the small size of some subgroups, for the purposes of statistical analysis, the values of some qualitative variables were recoded (simplified) [30]. The protocol for this study was approved by the Bioethical Committee of the Medical University of Silesia in Katowice (KNW/0022/KB1/146/14; 24 December, 2014, Katowice, Poland).

\section{Results}

There were initially 1118 volunteers in the study, of which 463 complete responses to the questionnaire qualified for the final analysis. The final number of participants was influenced by the dropout rate of $58.6 \%$ (more than half of the participants did not participate in all stages of the 
study). Detailed data were presented in our previous publication [29]. Both groups were comparable in terms of demographic characteristics and oncological history [29,30]. At the beginning of the study, we initially assessed the level of anxiety in both groups. No statistically significant differences were found in the levels of anxiety declared in the initial survey by the members of the control and intervention groups $\left(p=0.28, \chi^{2}\right.$ test).

Among the examples of diseases listed in the questionnaire, the highest level of anxiety (score of five on a five-point Likert scale) was most often declared for the possibility of developing cancer at $56 \%$ and $59 \%$ in the control and intervention groups, respectively. The highest level of anxiety was most rarely declared in the case of influenza, with only $4.3 \%$ and $0.4 \%$ of respondents in the control and intervention group, respectively (full report available in Table S1).

\subsection{Does the Level of Anxiety Depend on Knowledge about Cancer?}

CKI values in the initial survey were not associated with the declared level of anxiety related to developing cancer ( $p=0.72$ in Cochran-Mantel-Haenszel test; full report is available in Table 1). Similarly, differences in levels of anxiety caused by other diseases listed in the questionnaire were statistically insignificant.

Table 1. Descriptive statistics of the variable assessing differences in the severity of cancer-related anxiety in the subgroups defined by the tertile distribution of Cancer Knowledge Index (CKI) value.

\begin{tabular}{ccccc}
\hline \multirow{2}{*}{$\begin{array}{c}\text { Level of } \\
\text { Cancer-Related } \\
\text { Anxiety }\end{array}$} & Overall & Low & Medium & High \\
\cline { 2 - 5 } & $N=\mathbf{4 6 3}$ & $N=\mathbf{1 4 2}$ & $\mathbf{N = 1 8 2}$ & $\boldsymbol{N}=\mathbf{1 3 9}$ \\
\hline 1 & $24(5.2 \%)$ & $9(6.3 \%)$ & $13(7.1 \%)$ & $2(1.4 \%)$ \\
2 & $21(4.5 \%)$ & $9(6.3 \%)$ & $2(1.1 \%)$ & $10(7.2 \%)$ \\
3 & $57(12.3 \%)$ & $15(10.6 \%)$ & $18(9.9 \%)$ & $24(17.3 \%)$ \\
4 & $94(20.3 \%)$ & $21(14.8 \%)$ & $44(24.2 \%)$ & $29(20.9 \%)$ \\
5 & $267(57.7 \%)$ & $88(62.0 \%)$ & $105(57.7 \%)$ & $74(53.2 \%)$ \\
\hline
\end{tabular}

* 1 expresses the lowest and 5 highest levels of anxiety; ** level of statistical significance of the Cochran-Mantel-Haenszel test.

\subsection{Other Factors that May Affect the Level of Anxiety Associated with Cancer}

Participants with a positive family history of cancer significantly more often $(p<0.001)$ declared a higher level of anxiety associated with this group of diseases. The percentage of people who declared the maximum level of anxiety against cancer in the first group was $61.2 \%$, and $47.5 \%$ in the control group (negative family history of cancer).

In contrast, a significantly lower $(p=0.017)$ level of anxiety was declared by participants who had underwent oncological treatment (52.1\% with score of 5 and $8.3 \%$ with score of 4 ) compared to participants who did not (58.3\% with score of 5 and $21.7 \%$ with scores of 4$)$. A similar association $(p=0.02)$ was observed in the group of people diagnosed with cancer who declared less severe anxiety ( $50 \%$ score of 5 and $14 \%$ score of 4 ) than healthy people (58.6\% scoring 5 and $21.1 \%$ scoring 4 ). We did not find any other statistically significant differences in the self-assessment of anxiety associated with the possibility of developing cancer in the analyzed subgroups defined by selected demographic variables. The results are presented in Table 2 and Figure 1. 
Table 2. The level of cancer-related anxiety delineated by the respondents. Descriptive statistics together with differences tests in subgroups defined by selected variables.

\begin{tabular}{|c|c|c|c|c|c|c|c|}
\hline & \multirow[b]{2}{*}{ Overall } & \multicolumn{6}{|c|}{ Level of Anxiety (5-Point Likert Scale; 1 = Lowest, 5 = Highest) } \\
\hline & & 1 & 2 & 3 & 4 & 5 & \multirow{2}{*}{$p$} \\
\hline & $N=463$ & $N=24$ & $N=21$ & $N=57$ & $N=94$ & $N=267$ & \\
\hline \multicolumn{8}{|c|}{ Age (Years) } \\
\hline Median (IQR) & $33(22-47)$ & $42(27.5-62)$ & $33(22-56)$ & $35(26-48)$ & $29(20.2-46)$ & $33(22-45)$ & $0.1^{\mathrm{k}}$ \\
\hline \multicolumn{8}{|c|}{ Sex } \\
\hline Male & 179 (38.7\%) & $9(5.0 \%)$ & $9(5.0 \%)$ & $19(10.6 \%)$ & $42(23.5 \%)$ & $100(55.9 \%)$ & $0.93^{\&}$ \\
\hline Female & $284(61.3 \%)$ & $15(5.3 \%)$ & $12(4.2 \%)$ & $38(13.4 \%)$ & $52(18.3 \%)$ & $167(58.8 \%)$ & \\
\hline \multicolumn{8}{|c|}{ Place of Residence with the Number of Inhabitants * } \\
\hline$\leq 100,000$ & $218(47.1 \%)$ & $9(4.1 \%)$ & $8(3.7 \%)$ & $26(11.9 \%)$ & $45(20.6 \%)$ & $130(59.6 \%)$ & 0.2 \& \\
\hline$>100,000$ & $245(52.9 \%)$ & $15(6.1 \%)$ & $13(5.3 \%)$ & $31(12.7 \%)$ & $49(20.0 \%)$ & $137(55.9 \%)$ & \\
\hline \multicolumn{8}{|c|}{ Level of Education $* *$} \\
\hline Lower & $196(42.3 \%)$ & $9(4.6 \%)$ & $7(3.6 \%)$ & $24(12.2 \%)$ & $39(19.9 \%)$ & 117 (59.7\%) & $0.35^{\&}$ \\
\hline Higher & $267(57.7 \%)$ & $15(5.6 \%)$ & $14(5.2 \%)$ & $33(12.4 \%)$ & $55(20.6 \%)$ & $150(56.2 \%)$ & \\
\hline \multicolumn{8}{|c|}{ Occupation } \\
\hline Nonmedical & 388 (83.8\%) & $23(5.9 \%)$ & $16(4.1 \%)$ & $51(13.1 \%)$ & 78 (20.1\%) & 220 (56.7\%) & $0.17^{\&}$ \\
\hline Medical & $75(16.2 \%)$ & $1(1.3 \%)$ & $5(6.7 \%)$ & $6(8.0 \%)$ & $16(21.3 \%)$ & $47(62.7 \%)$ & \\
\hline \multicolumn{8}{|c|}{ Positive Family History of Cancer } \\
\hline No & $120(25.9 \%)$ & 15 (12.5\%) & $4(3.3 \%)$ & $19(15.8 \%)$ & $25(20.8 \%)$ & $57(47.5 \%)$ & $<0.001 \&$ \\
\hline Yes & $343(74.1 \%)$ & $9(2.6 \%)$ & $17(5.0 \%)$ & $38(11.1 \%)$ & $69(20.1 \%)$ & $210(61.2 \%)$ & \\
\hline \multicolumn{8}{|c|}{ Diagnosis of Cancer } \\
\hline No & $413(89.2 \%)$ & $18(4.4 \%)$ & $19(4.6 \%)$ & $47(11.4 \%)$ & $87(21.1 \%)$ & $242(58.6 \%)$ & $0.02^{\&}$ \\
\hline Yes & $50(10.8 \%)$ & $6(12.0 \%)$ & $2(4.0 \%)$ & $10(20.0 \%)$ & $7(14.0 \%)$ & $25(50.0 \%)$ & \\
\hline \multicolumn{8}{|c|}{ Treated for Cancer } \\
\hline No & $415(89.6 \%)$ & $18(4.3 \%)$ & $19(4.6 \%)$ & $46(11.1 \%)$ & 90 (21.7\%) & $242(58.3 \%)$ & 0.017 \& \\
\hline Yes & $48(10.4 \%)$ & $6(12.5 \%)$ & $2(4.2 \%)$ & $11(22.9 \%)$ & $4(8.3 \%)$ & $25(52.1 \%)$ & \\
\hline \multicolumn{8}{|c|}{ Self-Declaration of Cancer-Related Level of Knowledge } \\
\hline No & $362(78.2 \%)$ & $17(4.7 \%)$ & $16(4.4 \%)$ & $42(11.6 \%)$ & 71 (19.6\%) & $216(59.7 \%)$ & $0.12 \&$ \\
\hline Yes & $101(21.8 \%)$ & $7(6.9 \%)$ & $5(5.0 \%)$ & $15(14.9 \%)$ & $23(22.8 \%)$ & $51(50.5 \%)$ & \\
\hline \multicolumn{8}{|c|}{ Self-Declaration of Willingness to Improve the Level of Cancer-Related Knowledge } \\
\hline No & $35(7.6 \%)$ & $2(5.7 \%)$ & $2(5.7 \%)$ & $7(20.0 \%)$ & $6(17.1 \%)$ & $18(51.4 \%)$ & $0.34^{\&}$ \\
\hline Yes & $428(92.4 \%)$ & $22(5.1 \%)$ & $19(4.4 \%)$ & $50(11.7 \%)$ & $88(20.6 \%)$ & $249(58.2 \%)$ & \\
\hline
\end{tabular}

Note: IQR, interquartile range; k, Kruskal-Wallis test; \&, Cochran-Mantel-Haenszel test (nonzero correlation); * Villages and cities having $\leq 100,000$ inhabitants were combined to $\leq 100,000$ category; $* *$ Primary and secondary values were combined to form a single 'low' category, whereas both high school and high school medical were assigned to a 'high' category.

We additionally performed analysis with a logistic regression model that included the same variables as the descriptive statistics presented in Table 2 . We found a positive family history of cancer to be the only significant factor of the level of anxiety with an odds ratio of 4.18 (95\% confidence interval from 1.69 to $10.76, p=0.002$ ). 

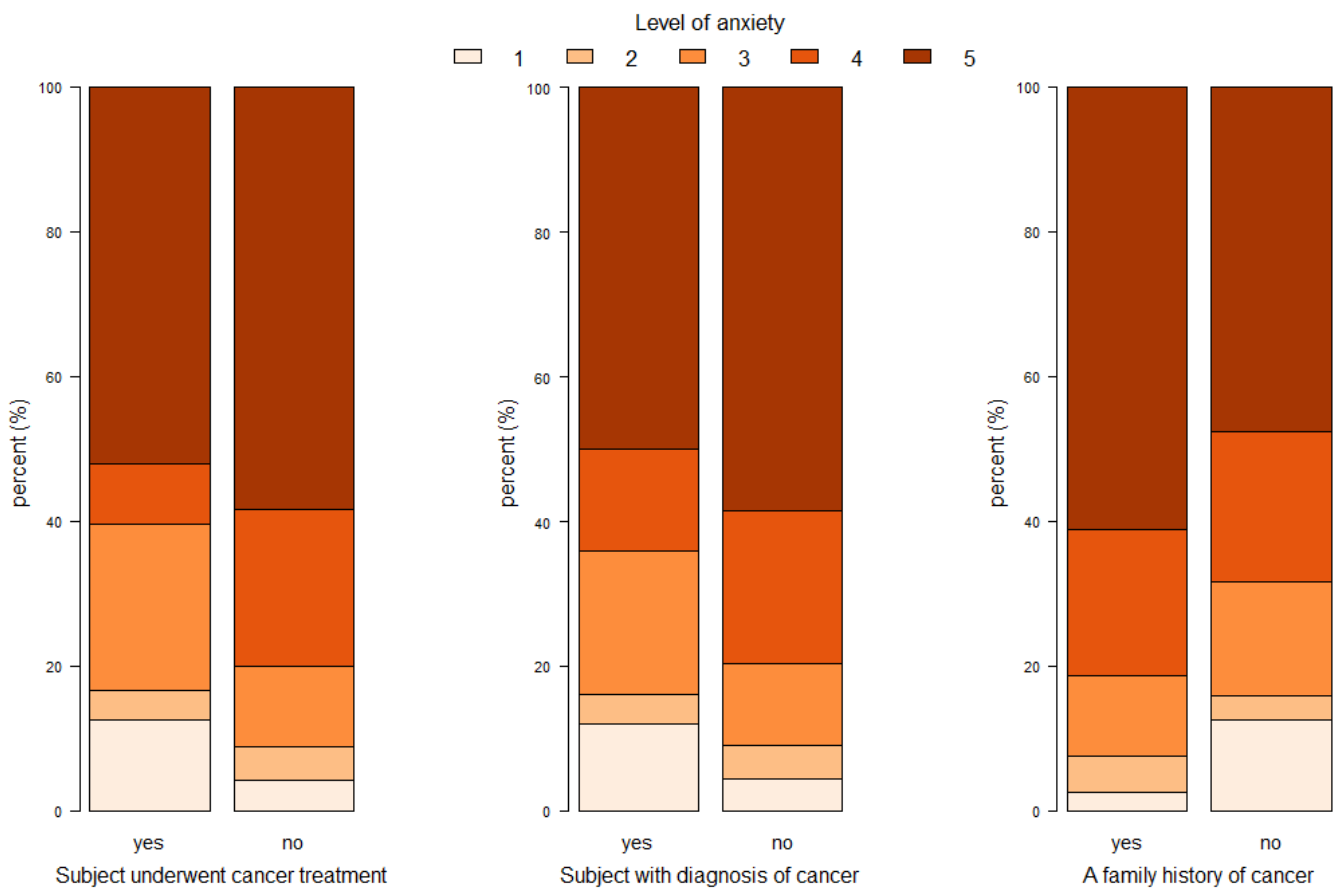

Figure 1. The level of anxiety depending on the declared burden of the individual and family history of cancer, as well as whether the subject had ever undergone oncological treatment.

\subsection{Impact of Educational Intervention on Level of Anxiety Associated with Cancer}

The conducted educational intervention reduced the declared level of anxiety associated with the possibility of developing cancer (Table 3, Figure 2).

Table 3. Differences in the level of anxiety associated with selected diseases: baseline and final assessment in intervention and control groups in terms of numbers and percentages (in brackets).

\begin{tabular}{ccccccc}
\hline \multirow{2}{*}{$\begin{array}{c}\text { Level of Cancer-Related } \\
\text { Anxiety }\end{array}$} & \multicolumn{2}{c}{ Intervention } & \multicolumn{3}{c}{ Control } \\
\cline { 2 - 6 } & Baseline & Final & $p^{* *}$ & Baseline & Final & $p^{* *}$ \\
\hline 1 & $15(7.2 \%)$ & $11(5.3 \%)$ & & $9(3.5 \%)$ & $10(3.9 \%)$ \\
2 & $12(5.8 \%)$ & $16(7.7 \%)$ & & $9(3.5 \%)$ & $11(4.3 \%)$ & \\
3 & $23(11.1 \%)$ & $34(16.4 \%)$ & 0.03 & $34(13.3 \%)$ & $26(10.2 \%)$ & 0.6 \\
4 & $41(19.8 \%)$ & $48(23.2 \%)$ & & $53(20.7 \%)$ & $67(26.2 \%)$ & \\
5 & $116(56.0 \%)$ & $98(47.3 \%)$ & & $151(59.0 \%)$ & $142(55.5 \%)$ & \\
\hline
\end{tabular}

* 1 expresses the lowest and 5 the highest level of anxiety; ${ }^{* *} p$, statistical significance in Wilcoxon test for paired variables.

The statistical analysis (Wilcoxon test for paired variables) showed that differences in anxiety levels before and after the intervention were statistically significant $(p=0.03)$. At the same time, no statistically significant differences were found in the control group $(p=0.6)$. Additionally, an ordinal regression model analysis (CLMM function of R software) confirmed these results. There were also no statistically significant differences in the intensity of anxiety associated with other disease entities included in the questionnaire. Moreover, none of the variables was statistically significantly associated with a change in the level of anxiety. A complete listing of all disease entities included in the questionnaire is provided in Supplementary Table S1. 


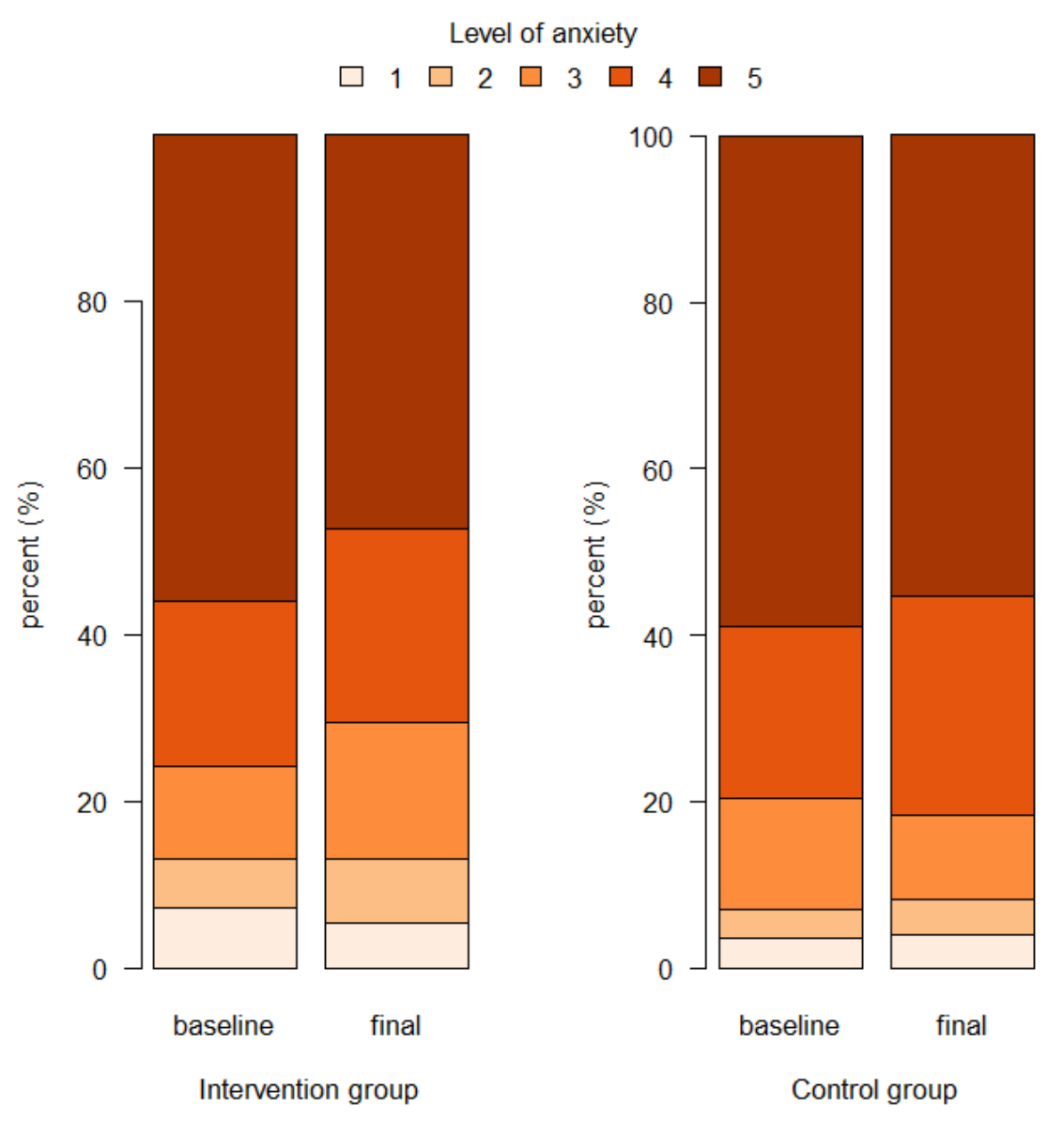

Figure 2. Self-declared baseline and final level of anxiety associated with cancer in intervention and control groups.

\section{Discussion}

Our previous analyses demonstrated that a higher level of education, age, medical occupation, and history of cancer may affect the decision to undergo necessary medical procedures $[29,30]$. Anxiety and embarrassment, along with lack of knowledge, misconceptions, and financial aspects are the main barriers to accessing cancer prevention [32-35]. Metwally et al. analyzed the entries published on Twitter to assess the views and attitudes of users of this social medium on screening for cancer. Fear and pain were common among negative tweets [36]. The search for the information can be an expression of a high level of anxiety, as was shown for people seeking information on human papillomavirus [37]. For example, about $66 \%$ of Polish women indicated fear of cancer as a reason for not undergoing mammography [33]. In this context, the possibility of using web-based decision aids to support decisions about screening mammography is promising [38].

The subjective nature of the assessment and the multifactorial determinants of anxiety can affect the final interpretation of the results and complicate comparisons. An additional complication in a direct comparison of the obtained results is the different methods of assessing the level of declared anxiety. In our study, a simple Likert scale, which was limited by the volume of the questionnaire, was used instead of an extensive validated psychometric tool. Ventura et al. conducted targeted interventions for reducing anxiety and depression in a group of 105 patients diagnosed with breast cancer. The study failed to achieve statistically significant improvement in the above outcomes [39]. The authors explained the lack of effects through methodological issues.

According to the results of the PORINA study presented here, the highest declared level of anxiety compared to others included in the questionnaire was induced by the possibility of developing cancer. Anxiety related to cancer has also become the subject of the Health Information National Trends Survey 
(HINTS) program that has been operating in the USA since 2003. It aims to obtain data about the knowledge and approach of the population to health, including cancer. Representative data on a national scale are obtained periodically by mail or telephone depending on the edition and are made available (https://hints.cancer.gov/) to researchers for further analysis [40]. As part of the fourth cycle of HINTS from 2014, the respondents were asked to assess their fears of developing cancer on a five-point scale. Every 10th respondent declared moderate (4/5) and significant $(5 / 5)$ anxiety levels at $13.2 \%$ and $8.8 \%$, respectively [40]. Therefore, these values are lower than those obtained in the PORINA study; nevertheless, a different population and slightly different questions in both studies should be noted.

Another important issue is the impact of the level of knowledge on anxiety. In the present study, we were not able to demonstrate that a low level of knowledge may be associated with a higher level of anxiety. As observed by Robb et al., an increase in knowledge did not lead to a significant change in the level of anxiety [25], in contrast to the results of our own research of a significant reduction in the intensity of declared anxiety after the educational intervention. Other authors pointed out that the level of cancer risk is an independent factor determining the increase in intensity of declared anxiety as a result of educational interventions [41]. Given the inconsistent results, it remains an open question whether the improvement of knowledge affects the level of anxiety. According to Bowen et al., the better the perception of risk factors and the higher the level of anxiety associated with cancer, the higher the effectiveness of interventions [42]. No such relationship was confirmed in our study; however, it seems appropriate to consider it in future studies.

\section{Advantages and Disadvantages}

In our opinion, the fact that Internet users are younger is an advantage of conducting interventions using this medium. In such a population, it should be easier to create the right attitudes, including those related to the state of health and prevention of cancer. Looking at the median age of the population in the PORINA study (33 years old), this should be considered one of the strengths of our study.

However, among the weaknesses of the study is the above-mentioned measurement of anxiety by self-declared answers on a simple Likert scale. Only one method of providing educational information (the Internet) was evaluated. Still, other researchers have previously shown the equivalence of interventions using video, text, and the Internet [43]. Given the low cost of conducting Internet interventions (and the aforementioned age of the target population), this is not a significant weakness of the study.

The main reason for the occurrence of a significant difference in the number of participants originally included in the study and the group qualified for the final analysis was the participants' resignation from further participation in the study. This is known as the dropout phenomenon (ratio of the number of people who completed the study to all enrolled), often resulting in lower response ratios and selection bias, which could have affect the results obtained. The dropout rate in our study $(58.6 \%)$ seems to be consistent with other authors' reports [44]. This topic was discussed in more detail in our first paper on the PORINA study [29].

\section{Conclusions}

The results of the study provide evidence that the use of Internet interventions aimed at increasing awareness could reduce anxiety levels associated with the possibility of developing cancer. The obtained results are promising for improving the frequency of participation in future medical procedures used to diagnose or treat cancer. However, it is necessary to verify the results in practice through a well-designed prospective study.

Supplementary Materials: The following is available online at http://www.mdpi.com/1660-4601/17/3/985/s1, Table S1: Differences in level of anxiety associated with selected diseases-baseline and final assessment in intervention and control groups.

Author Contributions: Conceptualization, M.G.; methodology, M.G. and M.K.; software, M.G.; validation, M.G.; formal analysis, M.G.; investigation, M.G.; resources, M.G.; data curation, M.G.; writing-original draft 
preparation, M.G.; writing-review and editing, M.G. and M.K.; visualization, M.G.; supervision, M.K.; project administration, M.G. and M.K.; funding acquisition, M.G. and M.K. All authors have read and agreed to the published version of the manuscript.

Funding: The APC was funded by Medical University of Silesia, Poland (KNW-1-154/K9/0). This research received no additional external funding.

Acknowledgments: The authors would like to thank all the volunteers who took part in the study. In addition, we would like to express our gratitude to Felix Danso (Cleveland State University) for improvements to the English language of this manuscript.

Conflicts of Interest: The authors declare no conflict of interest.

\section{References}

1. Chojnacka-Szawłowska, G.; Majkowicz, M.; Basiński, K.; Zdun-Ryżewska, A.; Wasilewko, I.; Pankiewicz, P. Knowledge of cancer symptoms and anxiety affect patient delay in seeking diagnosis in patients with heterogeneous cancer locations. Curr. Probl. Cancer 2017, 41, 64-70. [CrossRef] [PubMed]

2. Chojnacka-Szawłowska, G.; Kościelak, R.; Karasiewicz, K.; Majkowicz, M.; Kozaka, J. Delays in seeking cancer diagnosis in relation to beliefs about the curability of cancer in patients with different disease locations. Psychol. Health 2013, 28, 154-170. [CrossRef] [PubMed]

3. American Cancer Society. Cancer Facts E Figures 2016; American Cancer Society: Atlanta, GA, USA, 2016.

4. Sielska, J.; Matecka, M.; Dabrowska, E.; Jakubek, E.; Urbaniak, M. What do women know about breast cancer prophylaxis and a healthy style of life? Reports Pract. Oncol. Radiother. 2015, 20, 321-327. [CrossRef] [PubMed]

5. McCutchan, G.M.; Wood, F.; Edwards, A.; Richards, R.; Brain, K.E. Influences of cancer symptom knowledge, beliefs and barriers on cancer symptom presentation in relation to socioeconomic deprivation: A systematic review. BMC Cancer 2015, 15, 1000. [CrossRef]

6. Quaife, S.; Forbes, L.; Ramirez, A.; Brain, K.; Donnelly, C.; Simon, A.; Wardle, J. Recognition of cancer warning signs and anticipated delay in help-seeking in a population sample of adults in the UK. Br. J. Cancer 2014, 110, 12-18. [CrossRef]

7. Simon, A.E.; Waller, J.; Robb, K.; Wardle, J. Patient delay in presentation of possible cancer symptoms: The contribution of knowledge and attitudes in a population sample from the United Kingdom. Cancer Epidemiol. Biomark. Prev. 2010, 19, 2272-2277. [CrossRef]

8. Hvidberg, L.; Wulff, C.N.; Pedersen, A.F.; Vedsted, P. Barriers to healthcare seeking, beliefs about cancer and the role of socio-economic position: A Danish population-based study. Prev. Med. (Baltim) 2015, 71, 107-113. [CrossRef]

9. Hvidberg, L.; Pedersen, A.F.; Wulff, C.N.; Vedsted, P. Cancer awareness and socio-economic position: Results from a population-based study in Denmark. BMC Cancer 2014, 14, 581. [CrossRef]

10. Paddison, J.S.; Yip, M.J. Exploratory study examining barriers to participation in colorectal cancer screening. Aust. J. Rural. Health 2010, 18, 11-15. [CrossRef]

11. Turhal, N.S.; Dane, F.; Ulus, C.; Sari, S.; Senturk, N.; Bingol, D. Cancer-related false knowledge in relatives of cancer patients and the general public. J. BUON 2010, 15, 310-313.

12. Gansler, T.; Kaw, C.; Crammer, C.; Smith, T. A population-based study of prevalence of complementary methods use by cancer survivors: A report from the American cancer society's studies of cancer survivors. Cancer 2008, 113, 1048-1057. [CrossRef]

13. Nowara, E.; Suwiński, R. Impact of educational differences as measure of socioeconomic status on survival for breast cancer patients. Contemp. Oncol. (Poznań, Poland) 2012, 16, 345-349. [CrossRef] [PubMed]

14. Adams, C.; Torode, J.; Henshall, S.; Cazap, E.; Ryel, A.L.; Grey, N. The World Cancer Declaration: From resolution to action. Lancet Oncol. 2011, 12, 1091-1092. [CrossRef]

15. Bender, J.L.; Jimenez-Marroquin, M.-C.; Jadad, A.R. Seeking support on facebook: A content analysis of breast cancer groups. J. Med. Internet Res. 2011, 13, e16. [CrossRef] [PubMed]

16. Bender, J.L.; Wiljer, D.; To, M.J.; Bedard, P.L.; Chung, P.; Jewett, M.S.; Matthew, A.; Moore, M.; Warde, P.; Gospodarowicz, M. Testicular cancer survivors' supportive care needs and use of online support: A cross-sectional survey. Support. Care Cancer 2012, 20, 2737-2746. [CrossRef] 
17. Roach, A.R.; Lykins, E.L.B.; Gochett, C.G.; Brechting, E.H.; Graue, L.O.; Andrykowski, M.A. Differences in cancer information-seeking behavior, preferences, and awareness between cancer survivors and healthy controls: A national, population-based survey. J. Cancer Educ. 2009, 24, 73-79. [CrossRef]

18. Wiljer, D.; Urowitz, S.; Barbera, L.; Chivers, M.L.; Quartey, N.K.; Ferguson, S.E.; To, M.; Classen, C.C. A Qualitative Study of an Internet-Based Support Group for Women with Sexual Distress Due to Gynecologic Cancer. J. Cancer Educ. 2011, 26, 451-458. [CrossRef]

19. Ahern, N.R. Using the internet to conduct research. Nurse Res. 2005, 13, 55-70.

20. Boulkedid, R.; Abdoul, H.; Loustau, M.; Sibony, O.; Alberti, C. Using and Reporting the Delphi Method for Selecting Healthcare Quality Indicators: A Systematic Review. PLoS ONE 2011, 6, e20476. [CrossRef]

21. Kaplowitz, M.D.; Hadlock, T.D.; Levine, R. A Comparison of Web and Mail Survey Response Rates. Public Opin. Q. 2004, 68, 94-101. [CrossRef]

22. Winzelberg, A.J.; Classen, C.; Alpers, G.W.; Roberts, H.; Koopman, C.; Adams, R.E.; Ernst, H.; Dev, P.; Taylor, C.B. Evaluation of an internet support group for women with primary breast cancer. Cancer 2003, 97, 1164-1173. [CrossRef] [PubMed]

23. Saab, M.M.; Reidy, M.; Hegarty, J.; O’Mahony, M.; Murphy, M.; Von Wagner, C.; Drummond, F.J. Men's Information-Seeking Behaviour Regarding Cancer Risk and Screening: A Meta-Narrative Systematic Review. Psychooncology 2017, 27, 410-419. [CrossRef] [PubMed]

24. Teo, C.H.; Ng, C.J.; Booth, A.; White, A. Barriers and facilitators to health screening in men: A systematic review. Soc. Sci. Med. 2016, 165, 168-176. [CrossRef] [PubMed]

25. Robb, K.A.; Miles, A.; Campbell, J.; Evans, P.; Wardle, J. Can cancer risk information raise awareness without increasing anxiety? A randomized trial. Prev. Med. (Baltim) 2006, 43, 187-190. [CrossRef]

26. Willems, R.A.; Bolman, C.A.W.; Mesters, I.; Kanera, I.M.; Beaulen, A.A.J.M.; Lechner, L. Short-term effectiveness of a web-based tailored intervention for cancer survivors on quality of life, anxiety, depression, and fatigue: Randomized controlled trial. Psychooncology 2017, 26, 222-230. [CrossRef]

27. Owen, J.E.; O'Carroll Bantum, E.; Pagano, I.S.; Stanton, A. Randomized Trial of a Social Networking Intervention for Cancer-Related Distress. Ann. Behav. Med. 2017, 51, 661-672. [CrossRef]

28. Beatty, L.; Koczwara, B.; Wade, T. Evaluating the efficacy of a self-guided Web-based CBT intervention for reducing cancer-distress: A randomised controlled trial. Support. Care Cancer 2016, 24, 1043-1051. [CrossRef]

29. Gajda, M.; Kowalska, M.; Zejda, J.E. Evaluation of the First Polish Web-Based Intervention Aimed at Improving Cancer Prevention (the PORINA Study). Int. J. Environ. Res. Public Health 2018, 15, 1167. [CrossRef]

30. Gajda, M.; Kowalska, M. The Web-Based Randomized Controlled Intervention as the Enhancer of Cancer Prevention. Medicina 2019, 55, 434. [CrossRef]

31. R Core Team, R. A Language and Environment for Statistical Computing. Available online: http://cran.rproject.org (accessed on 20 December 2019).

32. Lyttle, N.L.; Stadelman, K. Assessing awareness and knowledge of breast and cervical cancer among Appalachian women. Prev. Chronic Dis. 2006, 3, A125.

33. Najdyhor, E.; Krajewska-Kułak, E.; Krajewska-Ferishah, K. Knowledge of women and men about breast cancer prevention. Ginekol Pol. 2013, 84, 116-125.

34. The Lancet Oncology Cancer awareness campaigns: Dispelling the myths. Lancet. Oncol. 2013, 14, 97. [CrossRef]

35. Gesink, D.; Filsinger, B.; Mihic, A.; Norwood, T.A.; Sarai Racey, C.; Perez, D.; Antal, J.; Ritvo, P.; Vernich, L. Cancer screening barriers and facilitators for under and never screened populations: A mixed methods study. Cancer Epidemiol. 2016, 45, 126-134. [CrossRef] [PubMed]

36. Metwally, O.; Blumberg, S.; Ladabaum, U.; Sinha, S.R. Using Social Media to Characterize Public Sentiment Toward Medical Interventions Commonly Used for Cancer Screening: An Observational Study. J. Med. Internet Res. 2017, 19, e200. [CrossRef] [PubMed]

37. Verhoeven, V.; Baay, M.; Baay, P. People seeking health information about human papillomavirus via the internet have a very high level of anxiety. Sex. Health 2009, 6, 258-259. [CrossRef] [PubMed]

38. Elkin, E.B.; Pocus, V.H.; Mushlin, A.I.; Cigler, T.; Atoria, C.L.; Polaneczky, M.M.; Spatz, E.S.; Krumholz, H.M.; Moulton, B.W.; Cigler, T.; et al. Facilitating informed decisions about breast cancer screening: Development and evaluation of a web-based decision aid for women in their 40s. BMC Med. Inform. Decis. Mak. 2017, 17, 29. [CrossRef] 
39. Ventura, F.; Sawatzky, R.; Ohlen, J.; Karlsson, P.; Koinberg, I. Evaluation of a web-based educational program for women diagnosed with breast cancer: Why is the intervention effect absent? Stud. Health Technol. Inform. 2013, 192, 1132.

40. National Cancer Institute Health Information National Trends Survey. Available online: http://hints.cancer.gov/ (accessed on 31 January 2018).

41. Kye, S.Y.; Park, K.; Park, H.G.; Kim, M. Psychological impact of health risk appraisal of Korean women at different levels of breast cancer risk: Neglected aspect of the web-based cancer risk assessment tool. Asian Pac. J. Cancer Prev. 2012, 13, 437-441. [CrossRef]

42. Bowen, D.J.; Burke, W.; Hay, J.L.; Meischke, H.; Harris, J.N. Effects of web-based intervention on risk reduction behaviors in melanoma survivors. J. Cancer Surviv. 2015, 9, 279-286. [CrossRef]

43. Ilic, D.; Egberts, K.; McKenzie, J.E.; Risbridger, G.; Green, S. Informing men about prostate cancer screening: A randomized controlled trial of patient education materials. J. Gen. Intern. Med. 2008, 23, 466-471. [CrossRef]

44. de Vries, H.; Logister, M.; Krekels, G.; Klaasse, F.; Servranckx, V.; van Osch, L. Internet based computer tailored feedback on sunscreen use. J. Med. Internet Res. 2012, 14, e48. [CrossRef] [PubMed]

(C) 2020 by the authors. Licensee MDPI, Basel, Switzerland. This article is an open access article distributed under the terms and conditions of the Creative Commons Attribution (CC BY) license (http://creativecommons.org/licenses/by/4.0/). 